\title{
An algorithm for determination of a diffusion layer in powder elements
}

\author{
(C) GuInur R. Khalikova, ${ }^{+}$Tatiana A. Eneykina, and Roza F. Gatina* \\ Federal Government Enterprise «State Scientific-Research Institut of Chemical Products». \\ Svetlaya St., 1. Kazan, 420033. Tatarstan Republic. Russia. \\ Phone:+7 (843) 560-20-12, (843) 564-38-92.E-mail gniihp@bancorp.ru
}

\begin{abstract}
*Supervising author; ${ }^{+}$Corresponding author
Keywords: a double base ball powder, surface of thin section, depth of a deterred layer, resorcinol.
\end{abstract}

\begin{abstract}
It has been developed an algorithm for determination of a depth of the deterred zone in the double base ball powders (BP) with a high nitroglycerine (NGL) content (up to $18 \%$ by mass); this parameter was determined using the powder of CCHф 35/3.80 mark. The image of the surface of the studied powder sample was taken with an electron microscope. A sequence of a preparation of the surface of the thin section was determined, which was treated initially by the concentrated sulfuric acid with the resorcinol dissolved in it. The duration of the treatment with the concentrated sulfuric acid was established by means of the experiments. The optimum duration of the treatment with the acid is 2 minutes. Then the surface of the sample was washed with the hot distilled water and treated by $5 \%$ solution of the $\mathrm{KOH}$.

Thus, the treatment of the surface of the thin section by the acid with the resorcinol allowed not only to reveal the boundary between the deterred layer of the powder elements and the matrix, but also to remove the remaining particles of the abrasive and the defects of polishing, that is the sulfuric acid acted as a reagent of the chemical pickling. In order to clarify the surface of the thin section, observed in the microscope, it was treated with the crystal violet. The intensive green fluorescence is observed when the preparation is treated with the stated indicator. This additional treatment of the surface of the thin section with the crystal violet allowed to make the boundary between the deterred layer of the powder elements and the matrix more defined.

The photomicrographs of the studied sample of the double base ball powder of CCHф 35/3.80 mark, presented in this paper, confirm the possibility of using of the following compounds, such as the concentrated sulfuric acid with the resorcinol and the crystal violet indicator instead of the iodine or the bromine for a determination of a depth of a deterrent penetration.
\end{abstract}

\section{References}

[1] Measurement procedure of № O-4221. The ball powders. A determination of a depth of a deterred layer in powder elements by the microscopy method. (russian)

[2] Specifications Specs. 7277-325-07506808-2016. The lacquer powder. The general specifications. (russian)

[3] V.A. Balandina, D.B. Gurvich, M.S. Klescheva [et. al.]. An analysis of polymerizing plastics. Moscow: Chemistry. 1965. P.512. (russian)

[4] OST 07506808-153. The method of determination of a depth of a deterrent penetration in the powder elements. A treatment of the thin section with the crystalline violet. (russian) 